\title{
Investigation of the Active Biofilm Communities on Polypropylene Filter Media in a Fixed Biofilm Reactor for Wastewater Treatment
}

\section{Running Title: Wastewater Treating Biofilms in Polypropylene Media Reactors}

\section{Contributors:}

Iffat Naz ${ }^{1,2,3,4^{*}}$, Douglas Hodgson ${ }^{4}$, Ann Smith ${ }^{5}$, Julian Marchesi ${ }^{5,6}$, Shama Sehar ${ }^{7}$, Safia Ahmed ${ }^{3}$, JimLynch $^{8}$, Claudio Avignone-Rossa ${ }^{4}$, Devendra P. Saroj ${ }^{1 *}$

\section{Affiliations:}

${ }^{1}$ Department of Civil and Environmental Engineering, Faculty of Engineering and Physical Sciences, University of Surrey, Guildford GU2 7XH, United Kingdom

${ }^{2}$ Department of Biology, Scientific Unit, Deanship of Educational Services, Qassim University, Buraidah 51452, KSA

${ }^{3}$ Environmental Microbiology Laboratory, Department of Microbiology, Faculty of Biological Sciences, Quaidi-Azam University, Islamabad, Pakistan

${ }^{4}$ School of Biomedical and Molecular Sciences, Department of Microbial and Cellular Sciences, University of Surrey, Guildford GU2 7XH, United Kingdom

${ }^{5}$ Cardiff School of Biosciences, Cardiff University, Cardiff CF10 3AX, United Kingdom

${ }^{6}$ Centre for Digestive and Gut Health, Imperial College London, London W2 1NY, United Kingdom

${ }^{7}$ Centre for Marine Bio-Innovation (CMB),School of Biological, Earth and Environmental Sciences (BEES), University of New South Wales, Sydney, Australia

${ }^{8}$ Centre for Environment and Sustainability, Faculty of Engineering and Physical Sciences, University of Surrey, Guildford GU2 7XH, United Kingdom

*Corresponding authors: Dr Iffat Naz (iffatkhattak@yahoo.com); Dr Devendra P. Saroj (d.saroj@surrey.ac.uk)

Devendra P. Saroj (PhD, CEnv, FHEA)

Department of Civil and Environmental Engineering

Faculty of Engineering and Physical Sciences

University of Surrey, Surrey GU2 7XH, United Kingdom

E: d.saroj@surrey.ac.uk

$\mathrm{T}:+44-0-1483686634$

This article has been accepted for publication and undergone full peer review but has not been through the copyediting, typesetting, pagination and proofreading process, which may lead to differences between this version and the Version of Record. Please cite this article as doi: 10.1002/jctb.5686 


\title{
Acknowledgements
}

The authors sincerely acknowledge the International Research Support Program (IRSIP) of the Higher Education Commission of Pakistan (HEC, Pakistan) for supporting IN for research work at the University of Surrey (UK). The contributors CAR, DH, AS and JM were partially supported by the UK Biotechnology and Biological Sciences Research Council (BBSRC) grants BB/J01916X/1 and BB/J019143/1.

\begin{abstract}
BACKGROUND: This research is focused on the effect of temperature on the growth of active biofilms on polypropylene (PP) filter media in aerobic fixed biofilm reactors (FBR) for wastewater treatment.

RESULTS: High-throughput sequencing was used to explore the composition and diversity of the microbial community of 14-days old (starting phase) biofilms grown at 10, 20 and $30^{\circ} \mathrm{C}$. Members of the classes Proteobacteria, Bacteroidetes, and Firmicutes were predominant in all the biofilm samples retrieved from PPFBRs. A total of 108 genera of bacteria were identified, with some of them present in all three reactors, including Trichococcus, Zoogloea, Aeromonas, Acidovorax, and Malikias, among others. Besides these shared populations, certain genera were abundantlyfound in individual biofilm samples, like Brevundimonas (17.1\%), Chitinimonas (10.3\%) and Roseateles $(39.3 \%)$, at 10,20 , and $30^{\circ} \mathrm{C}$, respectively. The metabolic capabilities of active microbial communities in PP-FBRs were estimated by assessing the changes in different variables (BOD, $\mathrm{DO}$, and $\mathrm{pH})$ in the influent and effluent during operation. A note worthy BOD removal (66.6\%) was shown by PP-FBRs operating at $30^{\circ} \mathrm{C}$, as compared to $20^{\circ} \mathrm{C}(28.3 \%)$ and $10^{\circ} \mathrm{C}(28.8 \%)$,consistent with the DO levels recorded in the effluents, highest at $30^{\circ} \mathrm{C}(70.5 \%)$, and decreasing with the declining temperatures. Substantial wastewater treatment efficiencies were observed in the reactors at $30^{\circ} \mathrm{C}$, attributable to the higher relative and diversity of microbial biofilms.
\end{abstract}

This article is protected by copyright. All rights reserved. 
CONCLUSIONS: The development of physiologically active biofilms in $\mathrm{PP}$ at all prevailing temperatures strongly suggests that the material is suitable to be employed in FBRs for wastewater treatment at different operational temperatures.

Key Words: Biofilm technologies; Microbial community composition; Municipal wastewater; Polypropylene filter media; Fixed biofilm reactor

\section{INTRODUCTION}

The challenges associated with wastewater treatment, such as rising energy costs, increasingly stringent effluent requirements, quality controls, and limited land for treatment plants, have led to the development of innovative and efficient technologies with high capacity. Biological methods play a crucial role in wastewater treatment. ${ }^{1}$ Biofilm-based technologies for the treatment of municipal and industrial wastewater were developed to overcome several disadvantages faced by conventional activated sludge systems and often produce higher effluent quality. ${ }^{2}$ The performance of biological wastewater treatment processes are determined by the activity of microorganisms. ${ }^{3,4}$ Therefore, it is essential to gain a detailed insight into the structure and function of the microbial community to explore its relation with the system performance, and to assist in the design of tailored systems for the treatment of municipal wastewater. Culture-based and culture-independent methods were the first technologies for analyses of bacterial communities in the water treatment process, but often provide unrepresentative results. Molecular techniques like clone library, microarray, fluorescent in situ hybridization, and real-time polymerase chain reaction based on 16S rRNA gene analysis have expanded and improved our understanding of microbial communities in wastewater treatment. ${ }^{4,5}$

However, high-throughput next generation sequencing (NGS) methods provide a more powerful tool for high taxonomic resolution of complex microbial communities. ${ }^{6,7}$ Recently, NGS technology has been applied 
for the metagenomic characterization of microbial communities in domestic wastewater treatment processes, ${ }^{8}$ activated sludge in different WWTPs as well as in full-scale bioreactors. ${ }^{5}$ This technology has been effectively used to disclose the relations between the microbial community and pollutant removal in various wastewater treatment processes. ${ }^{5,9}$

The present study aims to investigate the taxonomic structure of metabolically active biofilms grown on polypropylene (PP) media and find a correlation with the efficiency of the aerobic treatment of wastewater in fixed biofilm reactors (FBRs) at different temperatures. The PP media have been used in the FBRs in the present research because of its availability, cost-effectiveness and durability. ${ }^{3}$ This research uses a novel approach of utilizing NGS to systematically characterizing and assessing the microbial communities in the biofilms grown on the PP media under varying temperature conditions in an engineered bioreactor system for wastewater treatment.To the best of our knowledge, this research study is the first application of NGS for characterization of biofilm samples on PP media, used in an FBR system for wastewater treatment. Such information is significant for the better operation, transformed engineering design, and management of the FBRs for wastewater treatment in areas with large seasonal temperature variation, especially in many developing countries.

\section{MATERIALS AND METHODS}

\subsection{Evaluation of support media}

Discarded polypropylene ping-pong balls, with a surface area $\left(4 \pi r^{2}\right)$ of $50.24 \mathrm{~cm}^{2}$, were selected as biofilm supporting media in an aerobic fixed biofilm reactor (FBR) for treatment of municipal wastewater. X-ray Photoelectron Spectroscopy (XPS) analysis was performed using a Theta Probe Spectrometer (ThermoFisher Scientific, East Grinstead, UK) for elemental quantification of the surfaces. The XPS spectra were acquired using a mono-chromated Al Ka X-ray source $(\mathrm{h} v=1486.6 \mathrm{eV})$, and analyzed using Avantage software (ThermoFisher Scientific, East Grinstead, UK).

\subsection{Experimental setup and operation}

The biofilm was allowed to develop on sterilized polypropylene (PP) balls using municipal wastewater as a seed $(300 \mathrm{~mL})$ in small reactors $(500 \mathrm{~mL})$ under aerobic conditions, using a continuous airflow rate of $4 \mathrm{~L} / \mathrm{min}$ (Fig. 1). All experiments were conducted in continuous mode in triplicate, with the addition of freshly collected municipal wastewater $(300 \mathrm{ml})$ to each experimental setup thrice, with hydraulic loading rate (HRT) of 4.6 days, 


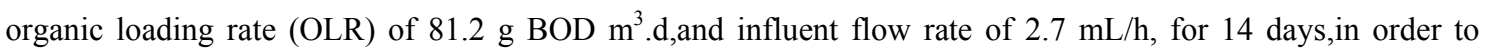
ensure the growth of a metabolically active biofilm atthree different temperatures $\left(10,20\right.$ and $\left.30^{\circ} \mathrm{C}\right) .{ }^{10}$ Finally, effluent samples were collected from all the reactors. Various physico-chemical parameters of the influent and effluent samples were analyzed during the experiment to check the physiological activity of the developing biofilms. $\mathrm{pH}$ was determined using a pH-meter (D-25 Horiba Water Quality Meter, Horiba Ltd, Japan); Dissolved oxygen (DO) levels were measured using a MM-60RMulti - Function Water Quality Meter, TOADKK, Japan) and biochemical oxygen demand $\left(\mathrm{BOD}_{5}\right)$ was evaluated by a 5-day BOD test according to 5210-B Standard Methods. ${ }^{11}$ Characteristics of municipal wastewater are available in the supplementary data in Table S1.

\subsection{Analysis of biofilm microbial communities}

Biofilms were removed by scraping the PP media surfaces and then washed with phosphate buffer (PBS). Then these biofilms were resuspended in the PBS, vortexed and centrifuged at $10,000 \times \mathrm{g}$ for $5 \mathrm{~min}$. Cell pellets were resuspendedin $100 \mu \mathrm{L}$ of sterile DNase and RNase free water (Promochem LGC) for DNA extraction using a Fast DNA SPIN Kit for Soil (MP Biomedicals). ${ }^{12}$ The quantity and purity of the extracted DNA were assessedwith a NanoDrop ND-1000 spectrophotometer (NanoDrop). For the amplification of bacterial 16S rRNA gene fragments, the PCR primers GAGTTTGATCNTGGCTCAG (forward) and GTNTTACNGCGGCKGCTG (reverse) were used. Different barcodes (Table S2) were incorporated between the 454 adapter and the forward primers to sort each biofilm sample from the mixed pyrosequencing outcomes. Each 50- $\mu 1$ reaction mixture included 1X EF-Taq buffer (Solgent, Daejeon, South Korea), 2.5 units of EF-Taq polymerase (Solgent), $0.2 \mathrm{mMdNTPmix}, 0.1 \mu \mathrm{M}$ of each primer and $100 \mathrm{ng}$ of template DNA. The temperature profile used was as follows: $95^{\circ} \mathrm{C}$ for $10 \mathrm{~min} ; 35$ cycles at $94^{\circ} \mathrm{C}$ for $45 \mathrm{sec}, 55^{\circ} \mathrm{C}$ for $1 \mathrm{~min}$ and $72^{\circ} \mathrm{C}$ for $1 \mathrm{~min}$, with a final extension at $72^{\circ} \mathrm{C}$ for $10 \mathrm{~min}$. The duplicate PCR products were pooled and purified using the QIAquick gel extraction kit (Qiagen, Hilden, Germany), and the purified products were used for pyrosequencing.

\subsection{Post-run analysisof nucleotide sequences.}

All partial 16S rRNA gene sequences were preprocessed initially using the Pyro-pipeline at the Ribosomal Database Project (RDP) to sort by barcode and remove primers and barcodes from the partial ribotags, and discard low quality and short $(<250$-bp long) sequences. These sequences were denoised and assembled into 
clusters using the precluster command to generate the fasta files datasets. These sequences were further analyzed through Mothur. The processed-sequenceswere clustered into Operational Taxonomic Units (OTUs) based on 0.97 sequence similarity with the Uclust algorithm. Representative OTUs were selected based on the most abundant sequences and taxonomic assignment was conducted using the RDP classifier. The software STAMP was used to calculate the $P$-values (ANOVA) for multiple groups/samples within the datasets. FastTree was used to create phylogenetic trees for UniFrac distance matrix construction in Mothur. Bacterial community richness and diversity indices (observed OTUs, Chaol estimator and ACE) and rarefaction curves were estimated at a cut-off set at 0.97 . For determination of beta-diversity (OTU based analysis) and Clustering (e.g. Heat maps), samples were rarefacted to reduce sequence heterogeneity. For the evaluation of the similarity in bacterial community composition among all three samples, the relative sequence at class and genus level for each sample was used to calculate pair wise similarities. All data were transformed by square root calculations and Bray Curtis similarity matrixes were generated using the software Primer v6 (PRIMER-E, Plymouth, UK). Pyrosequencing data were depositedto the European Nucleotide Archive (ENA) under secondary study accession number of ERP004725.To investigate the relationships between water chemical variables (BOD, pH and DO) and relative sequence at genera level within biofilm samples, Pearson's correlation coefficients (r) were calculated using PASW ${ }^{\circledR}$ Statistics 18.SPSS.

\section{RESULTS}

\subsection{Characterization of support media by XPS}

The intensity of photoelectrons as a function of binding energy is shown in Fig.2. Different peaks corresponding to various elements were observed in the XPS survey of the surface of PP medium. It was found that PP medium contains C Is (53.04\%), Ca 2p (0.98\%), N Is (3.05\%), O Is (39.96\%), S 2p (1.64\%), Si 2p (0.14\%) and Zn 2p3 (1.22\%).

\subsection{Sequencing and metagenomic assembly}

As shown in Table S3, a total of 2205 16S rRNA gene sequences were obtained, corresponding to 1016, 2050 and 1139 sequences reads at 10,20 , and $30^{\circ} \mathrm{C}$ respectively. After quality analysis, filtering and trimming, 610 sequences were annotated, corresponding to 163 high quality V4-V6 tags of the 16S rRNA-genes in library PP

$10^{\circ} \mathrm{C} ; 224$ in library PP $20^{\circ} \mathrm{C}$; and 223 in PP $30^{\circ} \mathrm{C}$. The numbers of OTUs, Chao 1 , and ACE at a cutoff level of $3 \%$, are shown in Table S3. The number of OTUs ranged from $163\left(\mathrm{PP} 10^{\circ} \mathrm{C}\right)$ to $224\left(\mathrm{PP} 20^{\circ} \mathrm{C}\right)$ and the patterns 
of Chao 1 and ACE values were very similar to the OTU numbers. The alpha diversity indices ranged from $8.6720\left(\mathrm{PP} 30^{\circ} \mathrm{C}\right)$ to $33.4449\left(\mathrm{PP} 10^{\circ} \mathrm{C}\right)$ and Good's coverage values varied from $0.898156\left(\mathrm{PP} 30^{\circ} \mathrm{C}\right)$ to $0.94878\left(\mathrm{PP} 20^{\circ} \mathrm{C}\right)$. Additionally, for a comparison of species' richness among the three samples, rarefaction curves were generated using a 3\% cutoff, indicated a large number of sequences in the biofilm retrieved from PP carriers at $20^{\circ} \mathrm{C}$ (Fig. 3).

\subsection{Biofilm community composition and taxonomic profiling}

Ribosomal Database Project (RDP) classifier was employed to assign the effective bacterial sequences to different phylogenetic taxa. In total, ten phyla were observed (Fig. 4). The phylum Proteobacteria accounted for the largest number of sequences (59.0\%) detected from all samples, accounting for $67.4 \%, 50.0 \%$, and $40.0 \%$ at 10,20 and $30^{\circ} \mathrm{C}$ biofilms respectively (Fig. 5). The other two dominant phyla were Bacteroidetes (20.0-26.6\%) and Firmicutes (3.6-20.0\%) of the entire community. These three groups, viz., Proteobacteria, Bacteroidetes, and Firmicuteswere predominant in all samples $(\sim 91 \%)$, with other bacterial phyla only accounting for $\sim 8 \%$. The phyla Actinobacteria, Acidobacteria, Planctomycetes and Gemmatimonadetes were detected in the biofilms developed at $10^{\circ} \mathrm{C}$ accounting for $1.8 \%$, while at $30^{\circ} \mathrm{C}$ all these phyla accounted for $17.7,1.2,2.0$ and 3.8 respectively. Moreover, Verrucomicrobia were found in biofilm samples at $20^{\circ} \mathrm{C}(6.7 \%)$ and $30{ }^{\circ} \mathrm{C}(1.6 \%)($ Fig. 5).

Within the phylum Proteobacteria, the Betaproteobacteria was the dominant class (47.0\%), followed by Gammaproteobacteria (21.0\%), Alphaproteobacteria (20.0\%), Deltaproteopacteria (8\%) and Epsilonproteobacteria (4\%) in all biofim samples (Fig. 6A). Within Betaproteobacteria, four orders were identified: Burkholderialeswas the most abundant order, accounting for $4.6 \%-44.5 \%$, followed by Rhodocyclales $(3.6-24.3 \%)$, while the orders Rhodobacteriales $(0.05-0.7 \%)$ and Nitrosomonadales $(0-0.4 \%)$ were present at much lower abundances (Fig. 7A).Within Bacteroidetes, the relative abundance of classes Sphingobacteria, Flavobacteria, and Bacteroidetes were $16.0 \%-63.9 \%, 8.9 \%-63.0 \%$, and $13.7 \%-75.0 \%$, respectively, in all samples (Fig. 6B). Sphingobacteria dominated the biofilms developed at $30^{\circ} \mathrm{C}$, with a relative abundance of $63.9 \%$, while Flavobacteria was prominent in the $10^{\circ} \mathrm{C}$ biofilms $(63.0 \%)$ and Bacteroidetes at $20^{\circ} \mathrm{C}(75.0 \%)$ biofilms (Fig. 6B). The phylum Firmicutes was the third most abundant, comprised of three classes Clostridia (21.0 - 62.0\%), Bacilli (23.0 - 38.0\%), and Erysipelotrichia (38.0-42.0\%).

However, Erysipelotrichia were not found in the biofilm at $30^{\circ} \mathrm{C}$ (Fig. 6C).

This article is protected by copyright. All rights reserved. 
A total of 32 known orders and 1 unknownorder were identified, using the RDP classifier (Table S3). From those, 13 orderswere present in all biofilm samples (Fig 7A), dominated by the orders Burkholderiales, Rhodocyclales, Lactobacillales, and Caulobacterales. The dominant orders accounted for 26.9\%, 20.9\%, $17.4 \%$ and $6.2 \%$ respectively. Several orders were distinctly detected in biofilms at $30^{\circ} \mathrm{C}$, such as Flavobacteriales, Myxococcales, Sphingobacteriales, Chlamydiales, Acidimicrobiales, Holophagales, Herpetosiphonales, Nitrosomonadales, Gemmatimonadales, and Planctomycetales and varied from0.1-3.5\% (Fig 7A).However, some orders like Actinomycetales (0.15\%), and Alteromonadales (0.21\%) were distinctly restricted to $10^{\circ} \mathrm{C}$ biofilms. While, Desulfobacteriales was found only at $20^{\circ} \mathrm{C}$ with relative of $0.21 \%$ (Fig 7A).

At the family level, a total of 53 families were found (Table S4), with Comamonadaceae, Rhodocyclaceae, Carnobacteriaceae, Caulobacteraceae, and Aeromonadaceae being the most abundant, accounting for 57.2, 48.8, 41.8, 17.8, 14.9\% respectively in all the samples (Fig. 7B). The relative abundance of Caulobacteraceae and Aeromonadaceae were higher at $10^{\circ} \mathrm{C}$, accounting for $17.1 \%$ and $13.2 \%$, respectively, as compared to their at $20^{\circ} \mathrm{C}(0.4$ and $1.1 \%$ respectively $)$ and $30^{\circ} \mathrm{C}(0.4$ and $0.6 \%$ respectively $)$. However, the relative abundance of Comamonadaceae was much higher at $30^{\circ} \mathrm{C}(40.5 \%)$, as compared to $10^{\circ} \mathrm{C}(13.8 \%)$ and $20^{\circ} \mathrm{C}(2.9 \%)$. Some families, like Nocardiaceae and Holophagaceaewere shared by all biofilm samples, at relative abundances below $1.0 \%$ (Fig. 7B).

On a finer scale, microbial communities of all samples were distributed in 108 genera of bacteria (Table S4). The top abundant genera in each biofilm sample were selected for generating the heatmap, which illustrated shared genera (Fig. 8). Among shared genera, the dominating genera were Trichococcus, Zoogloea, Aeromonas, Acidovorax, and Malikias (Fig. 8). The relative of these genera varies from $3.1-36.8 \%, 2.3-9.4 \%, 0.6-13.2 \%$, 0.4-9.1\% and $0.2-1.9 \%$ respectively in all three biofilm samples (Fig. 7C). The genera found only distinctly in the biofilms developed at $10^{\circ} \mathrm{C}$ were Undibacterium, Janthinobacterium, Bosea, Devosia, Gemmobacter, Paracoccus,Nubsella,Pedobacter, Microbacterium, and Shewanella, ranged from 0.1-1.7\%. Additionally, several genera were found to be abundant only in some biofilm samples. Aquincola, Brachymona, Diaphorobacter, Rhodoferax, Achromobacter, Camelimonas, and Dysgonomonas (relative <0.1\%) were restricted to the biofilms retrieved from $20^{\circ} \mathrm{C}$, while 32 genera were distinctly identified only in the biofilm samples removed from the reactors operating at $30^{\circ} \mathrm{C}$, and was dominated by Roseateles (39.3\%), Filimonas (5.5\%), Aquimonas (5.1\%), Fluviicola (2.7\%), Runella (2.5\%), Sediminibacterium (2.0\%), Mycobacterium (2.0\%), Byssovorax (2.0\%), Algoriphagus (1.9\%), Neochlamydia (1.0\%), Segetibacter (1.0\%). The relative abundance of the remaining 21 genera at $30^{\circ} \mathrm{C}$ were below $1 \%$. Some genera like Hydrogenophaga $(0.1-0.2 \%)$,

This article is protected by copyright. All rights reserved. 
Paludibacter (0.9-0.1\%), Phenylobacterium (0.2-0.3\%), Clostridium (0.1-1.4\%), were found in two samples of biofilms retrieved from 10 and $20^{\circ} \mathrm{C}$. A total 15 genera were found to be shared by 10 and $20^{\circ} \mathrm{C}$ biofilms, dominated by Brevundimonas (17.3\%), Dechloromonas (11.0\%),Propionivibrio (9.4\%), Quatrionicoccus (5.5\%), Sulfurospirillum (2.5\%), Stenotrophomonas (2.1\%), Uliginosibacterium (1.5\%), however other were much less $(<1.0 \%$ relative abundance). The genera Erythromicrobium was also detected in the biofilms developed at 10 and $30^{\circ} \mathrm{C}$, but not in the $20^{\circ} \mathrm{C}$ (Fig. 7C).

\subsection{Treatment efficiency of the aerobic FBR}

The correlation of the physico-chemical parameters of influent and effluent and number of species observed on PP media in the 10,20 and $30^{\circ} \mathrm{C} \mathrm{FBRs}$ is shown in Table 1. All parameters showed non-significant correlation, except BOD removal efficiency with the number of OTUs and temperature. Prevailing temperature conditions and operational taxonomic units (OTUs at 97\% similarity cut-off) recovered on PP- media were positively significantly correlated with each other $(P<0.01)$. While all other parameters have shown non-significant correlation $(P>0.05)$ with each other and also with OTUs and Invisimpson in case of all media reactors (Table 1). The values of $\mathrm{BOD}_{5}, \mathrm{DO}, \mathrm{pH}$ obtained from the influent and effluent of the FBRs are shown in Fig. 9.The BOD of the influent for all three reactors was $378.9 \mathrm{mg} / \mathrm{L}$. A highly significant BOD removal (66.6\%) was shown by reactors operating at $30^{\circ} \mathrm{C}$, decreasing from 378.9 to $126.36 \mathrm{mg} / \mathrm{L}$. The efficiencies of the reactors operated at $10^{\circ} \mathrm{C}$ and $20^{\circ} \mathrm{C}$ were comparable, with values of BOD of 269.13 and $267.34 \mathrm{mg} / \mathrm{L}$ respectively, corresponding to wastewater treatment efficiency of approximately $28 \%$.Another important parameter used to detect the performance of FBR was the increase in dissolved oxygen (DO). The DO of the influent was 1.9 $\mathrm{mg} / \mathrm{L}$, and the highest $\mathrm{DO}$ increase $(70.5 \%)$ was observed in the $30^{\circ} \mathrm{C}$ reactors, followed by the reactors at 20and $10^{\circ} \mathrm{C}$. The $\mathrm{pH}$ in the $30^{\circ} \mathrm{C}$ reactors increased from 7.3 in the influent to 7.4 in the effluent. A small change was observed at $10^{\circ} \mathrm{C}$, with a value of 7.2 in the effluent, while the $\mathrm{pH}$ of the effluent at $20^{\circ} \mathrm{C}$ dropped to 7.0.

\section{DISCUSSIONS}

We investigated the composition and diversity of physiologically active biofilms developed on polypropylene (PP) media in aerobic FBRs at different temperatures. The efficiency of wastewater treatment in FBRs is highly dependent on the filter medium, which provides the matrix for microbial attachment, growthand contact with pollutants for removal. Biofilter media, both synthetic and natural, have shown variation in supporting biofilms and their respective potential to degrade pollutants in wastewater. Synthetic media are usually preferred as they are less biodegradable, and provide good support for the biofilms oxidizing contaminants in sludge and 
wastewaters. $^{3}$ To be used in the FBRs, these media need to be durable andnon-reactive, and should sustain the growth of metabolically active biofilms, as the wastewater treatment effectiveness depends on the microbial communities of the biofilm and the filter media used as substratum. The elemental composition of the support media should be compatible with microbial growth. XPS analysis of the media for the evaluation of media was undertaken, which showed its compatibility with microbial growth as composed mostly of carbon, oxygen, nitrogen, zinc contents (Fig. 2).

\subsection{Biofilm community composition and diversity}

The effect of temperature on biofilm formation within PP-FBRs was explored after 14 days of the experiment. In order to investigate the composition of the bacterial community, 16S rRNA gene sequences were obtainedfrom biofilms grown at 10,20 , and $30^{\circ} \mathrm{C}$. The Chaol index estimated $290.8,367.6842$ and 398.5263 OTUs at a $3 \%$ cutoff for the 10,20 and $30^{\circ} \mathrm{C}$ biofilm samples, respectively, demonstrating that the highest bacterial diversity is observed in the biofilms grown at $30^{\circ} \mathrm{C}$. The same trend was calculated using other nonparametric diversity indices, such as ACE.Furthermore, the parameter Invisimpson was calculated as a measure of Alpha-diversity, as it provides an indication of the richness in a community with uniform evenness that would have the same level of diversity. The highest Invisimpson (dominance) of 33.4449 was found at $10^{\circ} \mathrm{C}$ (Table S3). The diversity and richness of the biofilm samples were noticeably lower than that of the municipal wastewater treatment systems. ${ }^{5,13,14}$ For a comparison of bacterial species richness among 3 biofilm samples, rarefaction curves of all the observed OTUs were developed (Fig.3). This curve persistently increased with the number of sequences in the samples and did not reach a plateau, demonstrating that further increases in sample size would yield more species and suggesting that minor species would have remained unidentified. The data presented here wasbased on the evaluation of 14-days old biofilms, capable of degrading pollutants in the wastewater. The biofilm sample retrieved at $30^{\circ} \mathrm{C}$ was the steepest, reflecting the highest species richness among the samples. The highest bacterial diversity was found in the biofilms developed on $30^{\circ} \mathrm{C}$, while the lowest diversity was found in the biofilms developed at $10^{\circ} \mathrm{C}$ (Table S3). Although the same municipal wastewater was used as an inoculating agent for biofilm development, these results show that different temperature ssupport biofilms with different diversity. ${ }^{15}$

As shown in Fig.5, Proteobacteria was the most dominant phylum in all three samples. This widespread and highly diverse phylum was reported to be dominant in pharmaceutical, petroleum refinery, industrial wastewater treatment plants (WWTPs), sewage, ${ }^{13}$ various municipal wastewater treatment plants and 
bioreactors. ${ }^{5,16,17}$ The phylum Proteobacteria included a very high level of bacterial metabolic diversity related to global carbon, nitrogen and sulfur cycling. ${ }^{18}$ Other phyla such as Bacteroidetes, Firmicutes and Actinobacteria were detected abundantly in all three biofilm samples, in agreement with published results for activated sludge processes. ${ }^{5}$ Bacteroidetes $(24.0 \%)$ was the second largest phylum represented by classes Sphingobacteria, Bacteroidetes and Flavobacteriia. Sphingobacteria have been identified as one of the main bacterial genera responsible for organic pollutant removal. ${ }^{19}$ The phylum Firmicutes, represented by members of Bacillaceae and Clostridiaceae, was the major bacterial phylum, accounting for $8.0 \%$ of the entire community. In this study, however, it was notable that Clostridiaceae accounts for $1.5 \%$, and was represented by only single genus Clostridium sensustricto, only in the biofilms developed at 20 and $30^{\circ} \mathrm{C}$. A possible explanation for this low abundance was that the growth of Clostridium strains is mediated by anaerobic fermentation. The other five bacterial phyla, only accounted for $6 \%$, with Verrucomicrobia (2.0\%), Gemmatimonadetes (1.0\%), Planctomycetes (1.0\%), Acidobacteria (1.0\%) and Cynobacteria (1.0\%) (Fig. 5). These phyla were reported to be widespread in other wastewater treatment systems. ${ }^{20}$ Bacteroidetes and Proteobacteria such as Flavobacterium, and Acinetobacter are heterotrophic carbon degraders isolated from municipal wastewater treatment system. ${ }^{21}$

\subsection{Shared taxonomic genera on polypropylene media material}

Genus level analysis can provide further detailed information on microbial adaptation to external conditions, such as temperature. The heatmap shows some core genera in all biofilms (Fig. 8). Among the commonly abundant genera, many have been identified in wastewater treatment processes. For instance, Trichococcus was a dominant microorganism of all pyrotags in sewage and appeared to be well adapted to the sewer infrastructure environment. ${ }^{22}$ Members of the genus exhibit various features that may have potential for biotechnological applications such as environmental bioremediation, extracellular polysaccharide production, lactic acid production from various carbohydrates, etc.. ${ }^{23}$ Dethlefsen et $a l^{24}$ also reported Trichococcus sp. from a wastewater treatment plant with the capability of precipitating crystals of calcium carbonate and struvite. Zoogloea was found in all samples (15.8\%) and was reported that fast-growing species resulted in the formation ofbiofimgranules. ${ }^{25}$ Previously, species of the genus Zoogloea were recognized to form zoogloeal matrices ${ }^{26}$ and are the main mediator for the flocculation of activated sludge processes. ${ }^{27}$ Zoogloea was also identified to be potential phosphate accumulating organisms (PAOs). ${ }^{28}$ The genus Aeromonas (14.95\%) was present in all samples, but surprisingly most abundant in the $10^{\circ} \mathrm{C}$ biofilms. However, an increase of its strain (Aeromonas

This article is protected by copyright. All rights reserved. 
hydrophila) was observed in summer in raw sewage, treated wastewater and effluent-carrying canal. In summer, Aeromonas sp. demonstrated multiple resistance patterns towards antimicrobials, ${ }^{29}$ resistant to nalidixic acid in the wastewater ${ }^{30}$, and are recognized carriers of antibiotic resistance in wastewater habitats. ${ }^{31}$ Antimicrobial residues found in municipal wastewater may increase selective pressure on microorganisms for development of resistance. However, Aeromonas was reported for exoprotease production or biofilm formation though quorum sensing via N-acylated-1-homoserine lactones (AHLs) in activated sludge. ${ }^{32}$ Aeromonas sp. can grow both aerobically and anaerobically in a mesophilic environment by using a wide range of carbohydrate sources. ${ }^{33}$ Acidovorax $(10.67 \%)$ was present in all biofilm samples with high abundance at $10^{\circ} \mathrm{C}$. It was reported that Acidovorax sp. responsible for phosphate removal, ${ }^{34}$ and is among the first colonizers of diatom microaggregates. ${ }^{35}$ It was also found in activated sludge along with other species. ${ }^{36}$ Rhodococcus was found in all biofilm samples with low relative abundance. Rhodococcus sp. could perform heterotrophic nitrification and aerobic denitrification in wastewater treatment. ${ }^{37}$ It was previously isolated from a bioreactor with extensive phosphorus removal, ${ }^{38}$ and are also considered to be potential PAOs. ${ }^{28}$ Zhu et al ${ }^{14}$ studied the biodegradation characteristics of quinoline (and its intermediates) by Rhodococcus sp. isolated from activated sludge of a coke plant wastewater treatment process.A genus belonging to the family Rhodocyclaceae, Malikia sp., identified as a potential PAO, was also found in all biofilms. ${ }^{39}$ Rhodocyclaceae and Comamonadaceae were the core families in many wastewater treatment plants reported to be responsible for denitrifying and aromatic degrading processes. $^{40}$

\subsection{Distinct taxonomic genera on polypropylene filter media}

The relatively large numbers of genera weredistinctly detected in biofilm samples retrieved from $30^{\circ} \mathrm{C}$.The composition of bacterial community in the biofilm developed at $30^{\circ} \mathrm{C}$ reactors shown the presence of representatives of all phyla, and a very large proportion of the genus Roseatales of Betaproteobacteria. Roseateles sp. areaerobic, heterotrophic bacteria, able to depolymerize aliphatic as well as aliphatic-aromatic co-polyesters. ${ }^{41,42}$

Other genus found at high abundances was Acinetobacter, is a strictly an aerobic chemoorganotrophic bacterium with an oxidative metabolism that plays a significant role in the detoxification of different

pollutants, ${ }^{43}$ and has been identified as a potential PAO. ${ }^{44}$ Mycobacteria have been previously isolated from wastewater and sludge, and its hydrophobicity is linked to the removal of insoluble compounds. ${ }^{45}$ The genus Aquimonas has been reported to be involved in nitrification processes in warm springs. ${ }^{42}$ Filimonasis an 
exopolymer-producing bacterium, previously isolated from fresh water. The genera Sediminibacterium and Fluvicola (Bacteroidetes) and a genus Byssovorax (Deltaproteobacteria) were also found in biofilms samples at this temperature. Members of the genus Sediminibacterium are reported to inhabit eutrophic reservoirs. ${ }^{46}$ Fluvicola and Aquimonas, were previousely reported that forming biofilms with greater microbial diversity.$^{47}$

Chloroflexi sp. and Gordonia sp. were found only at $30^{\circ} \mathrm{C}$ (Table S4). These genera present metabolic interactions with Cyanobacteria. Cyanobacteria accumulate products of photosynthesis, which are metabolized by members of Chloroflexi. ${ }^{48}$ Gordonia were also distinctly found at $30^{\circ} \mathrm{C}$, but at less relative abundance. Gordonia sp. are known to play an important role during wastewater treatment and in biofilters. ${ }^{49}$ It is an aerobic rubber-degrading bacterium, first isolated from water accumulated inside deteriorated automobile tyres. $^{50}$ Gordoniae are probably important in natural environments and are powerful candidates for bioremediation processes because of their capacity to degrade substituted and non substituted hydrocarbons, widespread toxic environmental pollutants, other xenobiotics, and natural compounds that are not readily biodegradable. ${ }^{49}$ Examples of this ability are the adhesive growth of several Gordonia strains during the biodegradation of rubber materials ${ }^{50}$ and the utilization of hydrophobic hydrocarbons by many species of this genus. ${ }^{51}$ The genus Erythromicrobium was also detecdted in the biofilms developed at 10 and $30^{\circ} \mathrm{C}$, suggesting involvement in the metabolism of iron and manganese within biofilms. ${ }^{52}$ The genus Erythromicrobium has also been reported to reduce heavy metals. ${ }^{53}$ This trait makes the bacterium as a prospective applicant for removing heavy metal ions from wastewaters.

Some genera like Hydrogenophaga and Clostridium were found in two samples of biofilms retrieved from 20 and $30^{\circ} \mathrm{C}$, PP-FBRs (Fig. 7C; Table S4). Hydrogenophaga was shown to play an important role in autohydrogenotrophic denitrification in a hollow fiber membrane biofilm reactor for nitrate removal from drinking water. ${ }^{5}$ Genera such as Aquincola, Brachymona, Diaphorobacter, Rhodoferax, Achromobacter, Camelimonas, and Dysgonomonas (relative $<0.1 \%$ ) were restricted to the biofilms retrieved from $20^{\circ} \mathrm{C}($ Fig. 7C; Table S4). The strain Aquincolaisstrictly an aerobic, previouly isolated from methyl tert-butyl ether (MTBE)-contaminated aquifer ${ }^{54}$, and a wastewater treatment plant ${ }^{55}$ and is one of the most efficient aerobic MTBE degraders. ${ }^{56}$ The genus Diaphorobacterhas the capability of carrying out simultaneous nitrification and denitrification. ${ }^{57}$ Diaphorobacter sp. were previously isolated from an industrial wastewater treatment plant utilizing 3-nitrotoluene (3-NT) as a sole source of carbon, nitrogenand energy, ${ }^{58}$ through the dihydroxylation of the benzene ring. ${ }^{59}$ Achromobacter sp. were isolated from wastewater reported to degradedi-n-Butylphthalate ${ }^{60}$. 
At the genus level, some species, including Undibacterium, Janthinobacterium, Bosea, Devosia, Gemmobacter, Paracoccus, Nubsella, Pedobacter, Microbacterium, and Shewanella were distinctly observed with very low abundances $(<0.1 \%)$ (Table S4; Fig. 7C). Surprisingly, some of them, like Microbacterium sp. was isolated from activated sludge as ethylhexyl phthalate (DEHP)-degradation strain and reported to have an optimal temperature of $25-35^{\circ} \mathrm{C} .{ }^{61}$ Other genera such a, Flavobacteriumwas found at 10 and $30^{\circ} \mathrm{C}$. However, its relative abundance was distinctly high at $10^{\circ} \mathrm{C}$ (Fig. 7C). These results were in accordance with Biswas et al..$^{62}$, who observed elevated levels of Flavobacterium in the winter in treatment plants. Recently, the strictly aerobic Flavobacterium was also isolated from a municipal wastewater treatment plant. ${ }^{63}$ Flavobacteria has been found to be abundant in wastewater treatment systems exhibiting good resistance to pollutants. ${ }^{14}$ They are able to low temperature protein degradation through the activity of psychrophilic proteases. ${ }^{5}$ This suggests the capability of degrading all types of protein in wastewater in the reactors at low temperatures.

A large number of genera (15) were found in both 10 and $20^{\circ} \mathrm{C}$ biofilms (Fig. 7C). Surprisingly, Brevundimonas was observed in the biofilms with high relative abundances at 10 and $20^{\circ} \mathrm{C}$, contrary to previous research, in which an optimal growth temperature of $30^{\circ} \mathrm{C}$ was reported. ${ }^{64}$ Brevundimonas sp. is an effective extracellular polymeric substance (EPS) producer $^{65}$ that can participate in an aerobic biofilm formation. Brevundimonas sp. participates in the biosorption of nickel, copper and lead from wastewater. ${ }^{65,66}$ Wang et al. ${ }^{67}$ isolated Brevundimonas sp. from activated sludge of a coking wastewater treatment plant and identified that it could utilize quinoline as the sole source of carbon, nitrogen, and energy, with an optimum temperature of $30^{\circ} \mathrm{C}$ and $\mathrm{pH}$ of 9.0. Another genus, Dechloromonas, was abundantly present at 10 and $20^{\circ} \mathrm{C}$. Prevousely, Dechloromonas sp. had been observed at relative abundance in an anaerobic and aerobic zone of biofilms as potential PAO. ${ }^{28}$ It was also shown that certain bacteria like Dechloromonas were responsible for nitrate reduction in wastewater. ${ }^{68}$ The genera Rheinheimera and Lactococcus sp.were also present in both biofilm samples, but with high relative abundance at $10^{\circ} \mathrm{C}$. Rheinheimera are able to easily degrade organic matter, ${ }^{69}$ while Lactococcus sp. can degrade organic carbon into lactate or acetate and could promote the growth of sulphate reducers. ${ }^{70}$

\subsection{Correlation between the Treatment efficiency of the FBR at different temperatures and bacterial} biofilms

In this study, correlations were detected between bacterial diversity indices and operational/functional parameters like temperature, BOD, DO, etc. (Fig. 9). While, a significant correlation was found between 
microbial communities (OTUs) and the operational temperature of the FBRs, which is in agreement with previous studies. ${ }^{16}$ The prevailing temperature has shown to affect ecosystem function, by influencing the components of diversity such as species composition with particular traits, positive species interactions, and functional redundancy. ${ }^{71}$ It has also been suggested that temperature was the most important factor affecting microbial community assembly. ${ }^{72}$ The effect of temperature on microbial growth and metabolism iswell documented by Brown et al. ${ }^{73}$ An increase in the growth rate and activity of bacterial biofilms might increase with an increase in water temperatures. ${ }^{74,75}$ Further, increase in temperature also accelerate microbial metabolic rates, which would promote the activities of the enzymes responsible for the degradation of organic matter, thus it might further determine changes in the composition of bacterial species. ${ }^{76}$ Another important factor affecting the microbial communities is the BOD in the influent wastewater. ${ }^{13}$ In the present study, same wastewater was used as feedstock for all the FBRs for treatment. Therefore, the influent BOD cannot be considered responsible for modifying the biofilm communities in the FBRs on PP media. Oxygen was considered as the most favorable electron acceptor for aerobic microbes to remove organic pollutants in the wastewater treatment processes. Oxygen supply determines the bacterial growth and biomass decay rates and influences bacterial composition. ${ }^{67}$ In the present study, we cannot attribute the distinct biofilm communities on PP media in the different FBRs, as the same DO levels were observed in the influents.

\section{CONCLUSIONS}

In this research, a greater diversity of bacterial populations was found in the biofilms at $30^{\circ} \mathrm{C}$, largenumber of sequences was observed at $20^{\circ} \mathrm{C}$, and dominance was shown by biofilms at $10^{\circ} \mathrm{C}$. The dominant bacterial classes within the biofilms were Betaproteobacteria, followed by Gammaproteobacteria, Alphaproteobacteria and Bacilli at $10^{\circ} \mathrm{C}$. While, at $20^{\circ} \mathrm{C}$, Betaproteobacteria population was found to dominate the bacterial community followed by Bacteroidetes and Firmicutes. However, the biofilm developed at $30^{\circ} \mathrm{C}$ constitutes representatives of all the phyla. An obvious difference was observed in the diversity and richness of the bacterial community composition in the biofilm samples developed at 10,20 and $30^{\circ} \mathrm{C}$. A very large proportion of genera Rosetales and Aeromonas were found to dominate the communities at 30 and $10^{\circ} \mathrm{C}$ respectively. However, at $20^{\circ} \mathrm{C}$, some of the genera like Zoogloea and Dechloromonas were coexisting. Further research may be carried out with more sampling events (more sequences) to explain the large fraction of OTUs in the biofilm samples for a detailed assessment of the abundance and the diversity. A significant reduction in BOD of the municipal wastewater was observed in the reactors operating at $30^{\circ} \mathrm{C}$, and to a lesser extent in the reactors operating at 10 
and $20^{\circ} \mathrm{C}$. The results show that polypropylene is a good filter media in the FBRs for wastewater treatment, with temperature being the only operational parameter affecting the microbial composition in the biofilm. The results indicate that a system for the biological treatment of wastewater can be constructed using inexpensive materials to support the bacterial biofilms.

\section{Conflict of interest}

The authors declare that they have no competing interests.

\section{References}

1. Lazarova $\mathrm{V}$ and Manem J. Innovative biofilm treatment technologies for water and wastewater treatment. ChemInform 31(32): (2000).

2. Arenskötter M, Baumeister D, Berekaa MM, Pötter G, Kroppenstedt RM, Linos A and Steinbüchel A. Taxonomic characterization of two rubber degrading bacteria belonging to the species Gordonia polyisoprenivorans and analysis of hyper variable regions of 16S rDNA sequences. FEMS Microbiol Lett 205: 277-282 (2001).

3. Khatoon N, Naz I, Ali MI, Ali N, Jamal A, Hameed A and Ahmed S. Bacterial succession and degradative changes by biofilm on plastic medium for wastewater treatment. J Basic Microbiol 54(7): 739-749 (2014).

4. Sehar S and Naz I. Role of the biofilms in wastewater treatment. Microbial Biofilms - Importance and Applications (ISBN 978-953-51-2435-1). In: Dhanasekaran D and Thajuddin N (edn) Crotia:Intech, 2016.

5. Zhang T, Shao MF and Ye L. 454 Pyrosequencing reveals bacterial diversity of activated sludge from 14 sewage treatment plants. ISME J 6(6):1137-1147 (2012).

6. Shendure J and Ji H. Next-generation DNA sequencing. Nature Biotechnol 26(10): 1135-45 (2008).

7. Shokralla S, Spall JL, Gibson JF and Hajibabaei M. Next generation sequencing technologies for environmental DNA research. Mol Ecol 21(8):1794-1805 (2012).

8. Ye L, Shao MF, Zhang T, Tong AHY and Lok S. Analysis of the bacterial community in a laboratoryscale nitrification reactor and a wastewater treatment plant by 454-pyrosequencing. Water Res 45(15): 4390-4398 (2011). 
9. Portune KJ, Pérez MC, Álvarez-Hornos FJ and Gabaldón C. Investigating bacterial populations in styrene-degrading biofilters by $16 \mathrm{~S}$ rDNA tag pyrosequencing. Appl Microbiol Biotechnol 99(1):3-18 (2015).

10. Naz I, Hodgson D, Smith A, Marchesi J, Ahmed S, Avignone-Rossa C and Saroj DP. Effect of the chemical composition of filter media on the microbial community in wastewater biofilms at different temperatures. RSC Adv 6 (106):104345-53 (2016).

11. APHA. Standard methods for the examination of water and wastewater.American Public Health Association, USA (2005).

12. Logan BE, Murano C, Scott K, Gray ND and Head IM. Electricity generation from cysteine in a microbial fuel cell. Water Res 39(5):942-952 (2005).

13. Ibarbalz FM, Figuerola EL and Erijman L. Industrial activated sludge exhibit unique bacterial community composition at high taxonomic ranks. Water Res 47(11):3854-3864 (2013).

14. Zhu X, Tian J, Liu C and Chen L. Composition and dynamics of microbial community in a zeolite biofilter-membrane bioreactor treating coking wastewater. Appl Microbiol Biotechnol 97(19):87678775 (2013).

15. Dumont E, Andres Y, Le Cloirec $\mathrm{P}$ and Gaudin F. Evaluation of a new packing material for $\mathrm{H}_{2} \mathrm{~S}$ removed by biofiltration. Biochem Eng J42 (2):120-127(2008).

16. Wang X, Hu M, Xia Y, Wen X and Ding K. Pyrosequencing analysis of bacterial diversity in 14 wastewater treatment systems in China. Appl Environ Microbiol 78 (19):7042-7047 (2012).

17. Gao P, Xu W, Sontag P, Li X, Xue G, Liu T and Sun W. Correlating microbial community compositions with environmental factors in activated sludge from four full-scale municipal wastewater treatment plants in Shanghai, China. Appl Microbiol Biotechnol 100 (10):4663-4673 (2016).

18. Ansola G, Arroyo P and Sáenz de Miera LE. Characterisation of the soil bacterial community structure and composition of natural and constructed wetlands. Sci Total Environ 473: 63-71 (2014).

19. Shangguan H, Liu J, Zhu Y, Tong Z and Wu Y. Start-up of a spiral periphyton bioreactor (SPR) for removal of $\mathrm{COD}$ and the characteristics of the associated microbial community. Biores Technol 193: 456-462 (2015).

20. Manefield M, Griffiths RI, Leigh MB, Fisher R and Whiteley AS. Functional and compositional comparison of two activated sludge communities remediating coking effluent. Environ Microbiol 7(5): 715-722(2005). 
21. Aslam Z, Im W-T, Kim MK. and Lee S-T. Flavobacterium granuli sp. nov., isolated from granules used in a wastewater treatment plant. Int J Sys Evol Microbiol 55(2):747-751(2005).

22. VandeWalle JL, Goetz G.W, Huse SM, Morrison HG, Sogin ML, Hoffmann RG and McLellan SL. Acinetobacter, Aeromonas and Trichococcus populations dominate the microbial community within urban sewer infrastructure. Environ Microbiol 14(9):2538-2552(2012).

23. Pikuta EV and Hoover RB. The genus Trichococcus. Lactic Acid Bacteria: Biodiversity and Taxonomy New York;Wiley, 2014, 135-45.

24. Dethlefsen L, Huse S, Sogin ML and Relman DA. The pervasive effects of an antibiotic on the human gut microbiota, as revealed by deep 16S rRNA sequencing. PLoS Biology 16(11):e280(2008).

25. Weissbrodt DG, Neu T, Lochmatter S and Holliger C. The biofilm granulation mechanisms depend on the predominant populations involved. In71st Annual Assembly of the SSM (No. EPFL-TALK196973) (2013).

26. Dugan PR, Stoner DL and Pickrum HM. The genus Zoogloea. In:The prokaryotes, Springer, New York, pp. 3952-3964 (1992).

27. Rosselló-Mora RA, Wagner M, Amann R and Schleifer KH. The of Zoogloea ramigera in sewage treatment plants. Appl Environ Microbiol 61(2):702-707(1995).

28. Heylen K, Vanparys B, Wittebolle L, Verstraete W, Boon N and De Vos P. Cultivation of denitrifying bacteria: optimization of isolation conditions and diversity study. Appl Environ Microbiol 72(4): 263743(2006).

29. Popovic NT, Kazazic SP, Strunjak-Perovic I, Barisic J, Klobucar RS, Kepec S and Coz-Rakovac R. Detection and diversity of aeromonads from treated wastewater and fish inhabiting effluent and downstream waters. Ecotoxicol Environ Saf 120:235-242(2015).

30. Varela AR, Nunes OC and Manaia CM. Quinolone resistant Aeromonas sp. as carriers and potential tracers of acquired antibiotic resistance in hospital and municipal wastewater. Sci Total Environ 542:665-671(2016).

31. Figueira V, Vaz-Moreira I, Silva M and Manaia CM. Diversity and antibiotic resistance of Aeromonas spp. in drinking and waste water treatment plants. Water Res 45(17):5599-5611(2011).

32. Morgan-Sagastume F, Boon N, Dobbelaere S, Defoirdt T and Verstraete W. Production of acylated homoserine lactones by Aeromonas and Pseudomonas strains isolated from municipal activated sludge. Can J Microbiol 51(11):924-933(2005).

This article is protected by copyright. All rights reserved. 
33. Farmer III JJ, Arduino MJ and Hickman-Brenner FW. The genera Aeromonas and Plesiomonas. InThe prokaryotes, Springer, New York, pp 564-596 (2006).

34. Ren Y, Wei $\mathrm{CH}$ and Xiao KJ. Characterisation of microorganisms responsible for EBPR in a sequencing batch reactor by using the 16S rDNA-DGGE method. Water SA 33:123-128(2007).

35. Knoll S, Zwisler W and Simon M. Bacterial colonization of early stages of limnetic diatom microaggregates. Aquat Microb Ecol 25(2):141-150(2001).

36. Kraigher B, Kosjek T, Heath E, Kompare B and Mandic-Mulec I. Influence of pharmaceutical residues on the structure of activated sludge bacterial communities in wastewater treatment bioreactors. Water Res 42(17):4578-4588(2008).

37. Chen P, Li J, Li QX, Wang Y, Li S, Ren T and Wang L. Simultaneous heterotrophicnitrification and aerobic denitrification by bacterium Rhodococcus sp. CPZ24. Bioresour Technol116:266-270(2012).

38. Kämpfer P, Dott W, Martin K and Glaeser SP. Rhodococcus defluvii sp. nov., isolated from wastewater of a bioreactor and formal proposal to reclassify [Corynebacteriumhoagii] and Rhodococcus equi as Rhodococcus hoagii comb. nov. Int J Syst Evol Microbiol 64(3):755-761(2014).

39. Spring S, Wagner M, Schumann P and Kampfer P. Malikia granosa gen. Nov., sp. nov., a Novel Polyhydroxyalkanoates and Polyphosphate Accumulating Bacterium Isolated from Activated Sludge, and Reclassification of Pseudomonas apinosa as Malikia spinosa Comb. Nov. Int J Syst Ecol Microbiol 55:621-629(2005).

40. Ma Q, Qu Y, Shen W, Zhang Z, Wang J, Liu Z and Zhou J. Bacterial community compositions of coking wastewater treatment plants in steel industry revealed by Illumina high-throughput sequencing. Biores Technol 179:436-443(2015).

41. Lee SH, Choe H, Kim SG, Park DS, Nasir A, Kim BK and Kim KM. Complete genome of biodegradable plastics-decomposing Roseateles depolymerans KCTC 42856 T (=61A T). J Biotechnol 220:47-48(2016).

42. Shah AA, Hasan F, Shah Z, Kanwal N and Zeb S. Biodegradation of natural and synthetic rubbers: a review. Int Biodeter Biodegr 83:145-157(2013).

43. Felföldi T, Székely AJ, Gorál R, Barkács K, Scheirich G, András J and Márialigeti K. Polyphasic bacterial community analysis of an aerobic activated sludge removing phenols and thiocyanate from coke plant effluent. Bioresour Technol 101(10):3406-3414(2010).

This article is protected by copyright. All rights reserved. 
44. Kong YH, Nielsen JL and Nielsen PH. Identity and Ecophysiology of Uncultured Actinobacterial Polyphosphate Accumulating Organisms in Full-Scale Enhanced Biological Phosphorus Removal Plants. Appl Environ Microbiol 71:4076-4085(2005).

45. Radomski N, Betelli L, Moilleron R, Haenn S, Moulin L, Cambau E and Lucas FS. Mycobacterium behavior in wastewater treatment plant, a bacterial model distinct from Escherichia coli and Enterococci. Environ Sci Technol 45(12):5380-5386(2011).

46. Qu JH and Yuan HL. Sediminibacterium salmoneum gen. nov., sp. nov., a member of the phylum Bacteroidetes isolated from sediment of a eutrophic reservoir. Int J Syst Evol Microbiol 58:21912194(2008).

47. Torres CI, Krajmalnik-Brown R, Parameswaran P, Marcus AK, Wanger G, Gorby YA and Rittmann, BE. Selecting anode-respiring bacteria based on anode potential: phylogenetic, electrochemical, and microscopic characterization. Environ Sci Technol 43(24):9519-9524(2009).

48. Nozhevnikova AN, Botchkova EA and Plakunov VK. Multi-species biofilms in ecology, medicine, and biotechnology. Microbiology 84(6):731-750(2015).

49. Bendinger B, Kroppenstedt RM, Klatte S and Altendorf K. Chemotaxonomic differentiation of coryneform bacteria isolated from biofilters. Int J Syst Bacteriol 42:474-486(1992).

50. Linos A, Steinbüchel A, Spröer C and Kroppenstedt RM. Gordonia polyisoprenivorans sp. nov., a rubber-degrading actinomycete isolated from an automobile tyre. Int J Syst Evol Microbiol 49(4):17851791(1999).

51. Xue Y, Xuesong X, Zhou P, Liu R, Liang F and Ma Y. Gordonia paraffinivorans sp. nov., ahydrocarbon-degrading actinomycete isolated from an oil-producing well. Int J Syst Evol Micriobiol 53:1643-1646(2003).

52. Ginige MP, Wylie J and Plumb J. Influence of biofilms on iron and manganese deposition in drinking water distribution systems. Biofouling 27(2):151-163(2011).

53. Yurkov V, Jappe $\mathrm{J}$ and Vermeglio A. Tellurite resistance and reduction by obligately aerobic photosynthetic bacteria. Appl Environ Microbiol 62(11):4195-4198(1996).

54. Rohwerder T, Breuer U, Benndorf D, Lechner $U$ and Müller RH. The alkyl tert-butyl ether intermediate 2-hydroxyisobutyrate is degraded via a novel cobalamin-dependent mutase pathway. Appl Environ Microbiol 72(6):4128-4135(2006).

This article is protected by copyright. All rights reserved. 
55. Lechner U, Brodkorb D, Geyer R, Hause G, Härtig C, Auling G and Rohwerder T. Aquincola tertiaricarbonis gen. nov., sp. nov., a tertiary butyl moiety-degrading bacterium. Int J Syst Evol Microbiol 57(6):1295-1303(2007).

56. Müller RH, Rohwerder $\mathrm{T}$ and Harms H. Carbon conversion efficiency and limits of productive bacterial degradation of methyl tert-butyl ether and related compounds. Appl Environ Microbiol 73(6):1783-1791(2007).

57. Khardenavis AA, Kapley A and Purohit HJ. Simultaneous nitrification and denitrification by diverse Diaphorobacter sp. Appl Microbiol Biotechnol 77(2):403-409(2007).

58. Singh D and Ramanathan G. Biomineralization of 3-nitrotoluene by Diaphorobacter species. Biodegradation 24(5):645-655(2013).

59. Singh D, Kumari A and Ramanathan G. 3-Nitrotoluene dioxygenase from Diaphorobacter sp. strains: cloning, sequencing and evolutionary studies. Biodegradation 25(4):479-492(2014).

60. Jin D, Kong X, Li Y, Bai Z, Zhuang G, Zhuang X and Deng Y. Biodegradation of di-n-Butyl Phthalate by Achromobacter sp. Isolated from Rural Domestic Wastewater. Int J Environ Res Public Health 12(10):13510-13522(2015).

61. Chen JA, Li X, Li J, Cao J, Qiu Z, Zhao Q, Xu C and Shu W. Degradation of environmental endocrine disruptor di-2-ethylhexyl phthalate by a newly discovered bacterium, Microbacterium sp. strain CQ0110Y. Appl Microbiol Biotechnol 74(3):676-682(2007).

62. Biswas K, Taylor MW and Turner SJ. Successional development of biofilms in moving bed biofilm reactor (MBBR) systems treating municipal wastewater. Appl Microbiol Biotechnol 98(3):14291440(2014).

63. Feng Q, Han L, Nogi Y, Hong Q and Lv J. Flavobacterium lutivivi sp. nov., isolated from activated sludge. Int J Syst Evol Microbiol 66:1394-1400(2016).

64. Ryu SH, Park M, Lee JR, Yun PY and Jeon CO. Brevundimonas aveniformis sp. nov., a stalked species isolated from activated sludge. Int J Syst Evol Microbiol 57:1561-1565(2007).

65. Reis PJ, Reis AC, Ricken B, Kolvenbach BA, Manaia CM, Corvini PF and Nunes OC. Biodegradation of sulfamethoxazole and other sulfonamides by Achromobacter denitrificans PR1.J Hazard Mater 280:741-749(2014).

66. Singh $\mathrm{N}$ and Gadi R. Bioremediation of $\mathrm{Ni}$ (II) and $\mathrm{Cu}$ (II) from wastewater by the nonliving biomass of Brevundimonas vesicularis. J Environ Chem Ecotox4(8):137-142(2012).

This article is protected by copyright. All rights reserved. 
67. Wang C, Zhang M, Cheng F and Geng Q. Biodegradation characterization and immobilized strains' potential for quinoline degradation by Brevundimonas sp. K4 isolated from activated sludge of coking wastewater. Biosci Biotechnol Biochem 79(1):164-170(2015).

68. Zielińska M, Rusanowska P, Jarząbek J and Nielsen JL. Community dynamics of denitrifying bacteria in full-scale wastewater treatment plants. Environ Technol 37(18):2358-2367(2016).

69. Poretsky RS, Bano N, Buchan A, LeCleir G, Kleikemper J, Pickering M and Hollibaugh JT. Analysis of microbial gene transcripts in environmental samples. Appl Environ Microbiol 71(7):41214126(2005).

70. Jiang F, Zhang L, Peng GL, Liang SY, Qian J, Wei L and Chen GH. A novel approach to realize SANI process in freshwater sewage treatment-Use of wet flue gas desulfurization waste streams as sulfur source. Water Res 47(15):5773-5782(2013).

71. Cabrol L and Malhautier L. Integrating microbial ecology in bioprocess understanding: the case of gas biofiltration. Appl Microbiol Biotechnol 90(3):837-849(2011).

72. Yuan $Z$ and Blackall LL. Sludge population optimisation: a new dimension for the control of biological wastewater treatment systems. Water Res 36(2):482-490(2002).

73. Brown JH, Gillooly JF, Allen AP, Savage VM and West GB. Toward a metabolic theory of ecology. Ecology 85(7):1771-1789(2004).

74. Ratkowsky DA, Olley J, McMeekin TA and Ball A. Relationship between temperature and growth rate of bacterial cultures. J Bacteriol 149(1):1-5(1982).

75. Sander BC and Kalff J. Factors controlling bacterial production in marine and freshwater sediments. Microb Ecol 26(2):79-99(1993).Lear G, Anderson MJ, Smith JP, Boxen K and Lewis GD. Spatial and temporal heterogeneity of the bacterial communities in stream epilithic biofilms. FEMS Microb Ecol 65(3):463-473(2008).

\section{List of Tables}

Table 1. Pearson correlation coefficient (r) for wastewater physico-chemical factors and number of OTUs observed (after the $3 \%$ cutoff) on Polypropylene filter media

\section{Legend of Figures}

This article is protected by copyright. All rights reserved. 
Figure1. Schematic of the aerobic polypropylene filter media fixed biofilm reactors operating at 10,20 and $30^{\circ} \mathrm{C}$.

Figure 2. X-ray Photoelectron spectrums (XPS Survey) of Polypropylene filter media for wastewater treatment.

Figure 3. Rarefaction curves of OTUs at $97 \%$ of sequence similarity for three biofilm samples.

Figure 4. Taxonomic assignments of 16S rRNA gene sequences, classified at phyla level, retrieved from all three the biofilm samples developed on polypropylene filter media at different temperatures.

Figure 5. Taxonomic assignments of 16S rRNA gene sequences retrieved from the biofilm samples developed on polypropylene filter media at 10,20 and $30^{\circ} \mathrm{C}$ in the aerobic reactors for wastewater treatment, at phyla level.

Figure 6. Microbial diversity of the dominating phyla (A) Proteobacteria, (B) Bacteroidetes and (C) Firmicutes at class level, retrieved from biofilms developed at 10,20 and $30^{\circ} \mathrm{C}$ in the Polypropylene filter media reactors for wastewater treatment.

Figure 7. Relative (\%) at (A) orders (B) families and (C) genera levels in the biofilm samples developed on polypropylene filter media at 10,20 and $30^{\circ} \mathrm{C}$ in an aerobic reactors.

Figure 8.Heatmap showing the most abundant species (relative $\geq 1 \%$ ) at genus level within biofilms retrieved from polypropylene filter media surfaces developed at 10,20 and $30^{\circ} \mathrm{C}$ in an aerobic reactor.

Figure9. Levels of BOD, DO and $\mathrm{pH}$ of the influent and effluent from Polypropylene filter media reactors at different temperatures $\left(10,20\right.$ and $\left.30^{\circ} \mathrm{C}\right)$

\section{Supporting Information}

Table S1- Physico-chemical properties of the influent (municipal wastewater) at different temperature conditions

Table S2. Barcodes used for different biofilm samples

Table S3. Mothur diversity indices of bacterial communities in three aerobic biofilm samples developed on polypropylene packing media for wastewater treatment

Table S4. The taxonomic classification of the bacterial communities retrieved from biofilm samples of the polypropylene media aerobic reactors, operating at 10,20 , and $30^{\circ} \mathrm{C}$ into the Phyla, classes, orders, families, and genera levels. 
Table 1. Pearson correlation coefficient (r) for wastewater physico-chemical factors and number of OTUs observed (after the $3 \%$ cutoff) on Polypropylene filter media

\begin{tabular}{|c|c|c|c|c|}
\hline Parameters & OTUs & Invisimpson & BOD & DO \\
\hline $\mathrm{BOD}_{5}$ & $0.00 * *$ & & & \\
\hline $\mathrm{DO}$ & $0.181(\mathrm{NS})$ & $0.000 * *$ & & \\
\hline $\mathrm{pH}$ & $0.994(\mathrm{NS})$ & $-0.991 *$ & $-0.402(\mathrm{NS})$ & \\
\hline $\mathrm{Temp}\left({ }^{\circ} \mathrm{C}\right)$ & $0.859(\mathrm{NS})$ & $-0.903(\mathrm{NS})$ & $0.000^{* *}$ & $0.874(\mathrm{NS})$ \\
\hline
\end{tabular}

Key: $n=9, p<0.01^{* *}, p<0.05^{*}, \mathrm{NS}=p>0.05$; a two tail test was used.

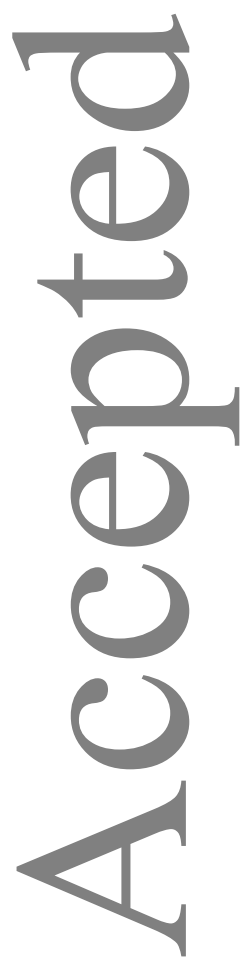




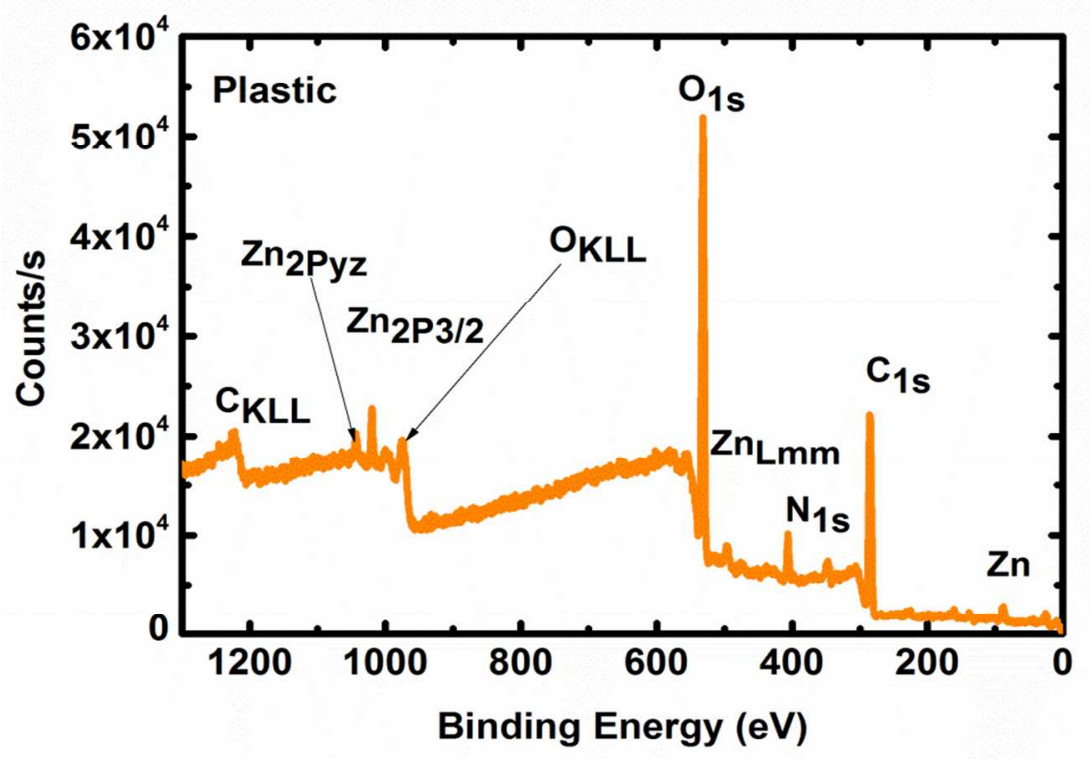

Fig. 2 


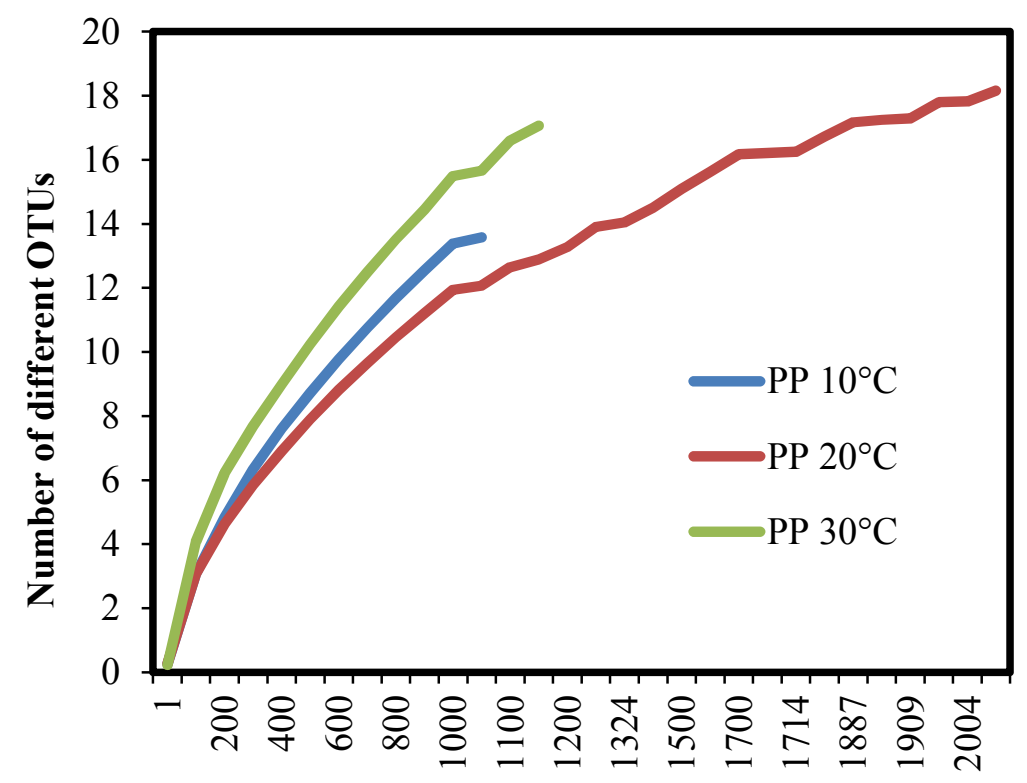

Number of sequences per sample

Fig.3 

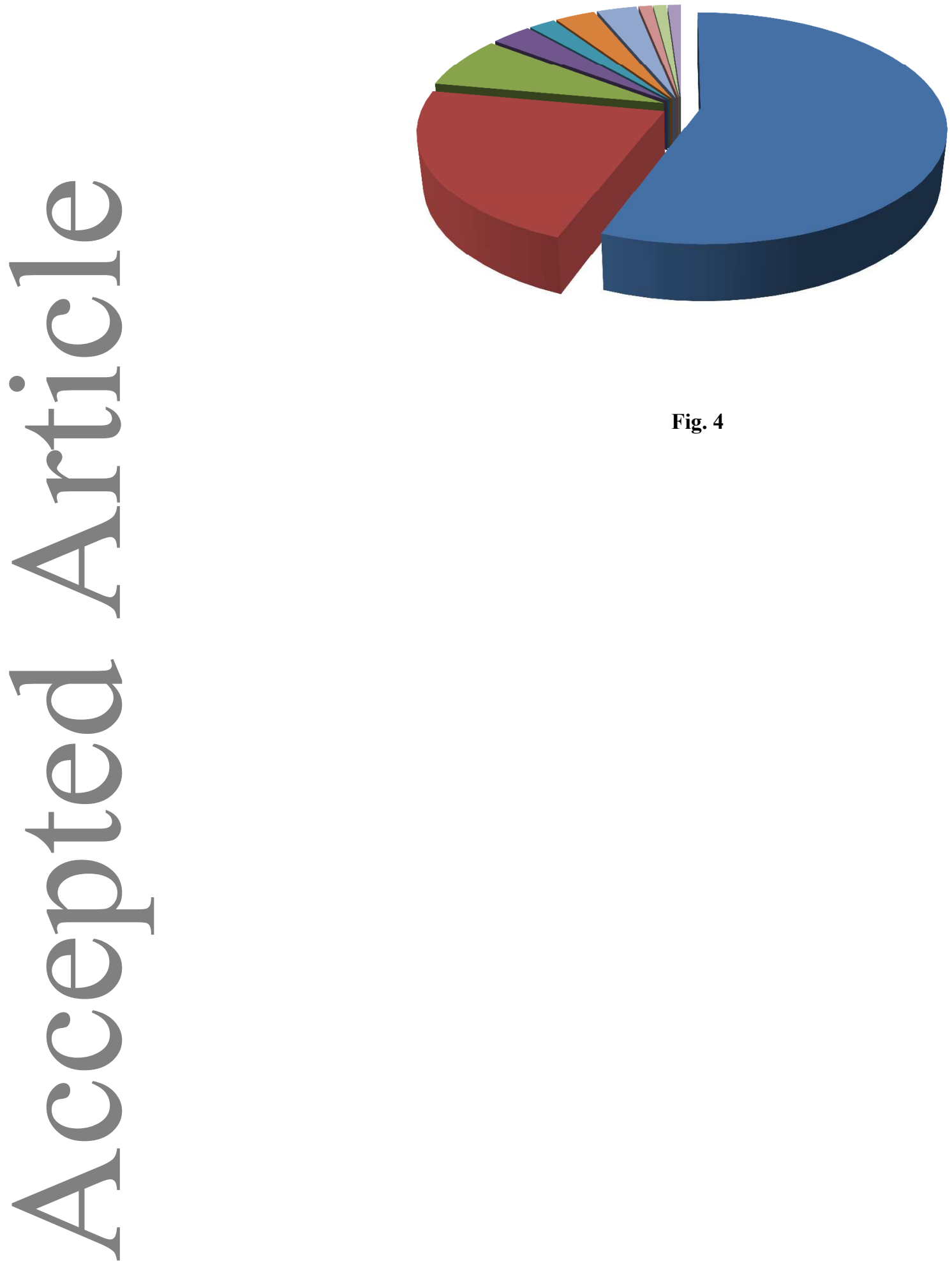

- Proteobacteria

- Bacteroidetes

Firmicutes

- Verrucomicrobia

- Gemmatimonadetes

- Planctomycetes

- Actinobacteria

- Acidobacteria

- Chlamydiae

- Chloroflexi

Fig. 4 


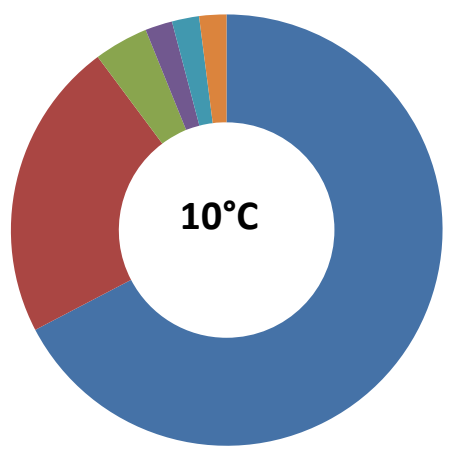

- Proteobacteria

- Bacteroidetes

- Firmicutes

- Actinobacteria

- Acidobacteria

- Cyanobacteria/Chloroplast

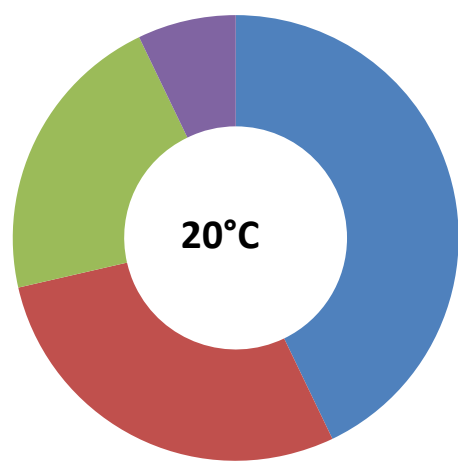

- Proteobacteria

- Bacteroidetes

Firmicutes

- Verrucomicrobia

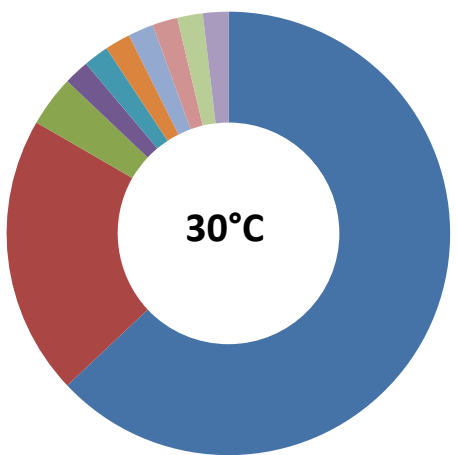

- Proteobacteria Bacteroidetes

Firmicutes

Actinobacteria

- Acidobacteria

- Gemmatimonadetes

- Chlamydiae

- Chloroflexi

- Verrucomicrobia

Fig. 5 


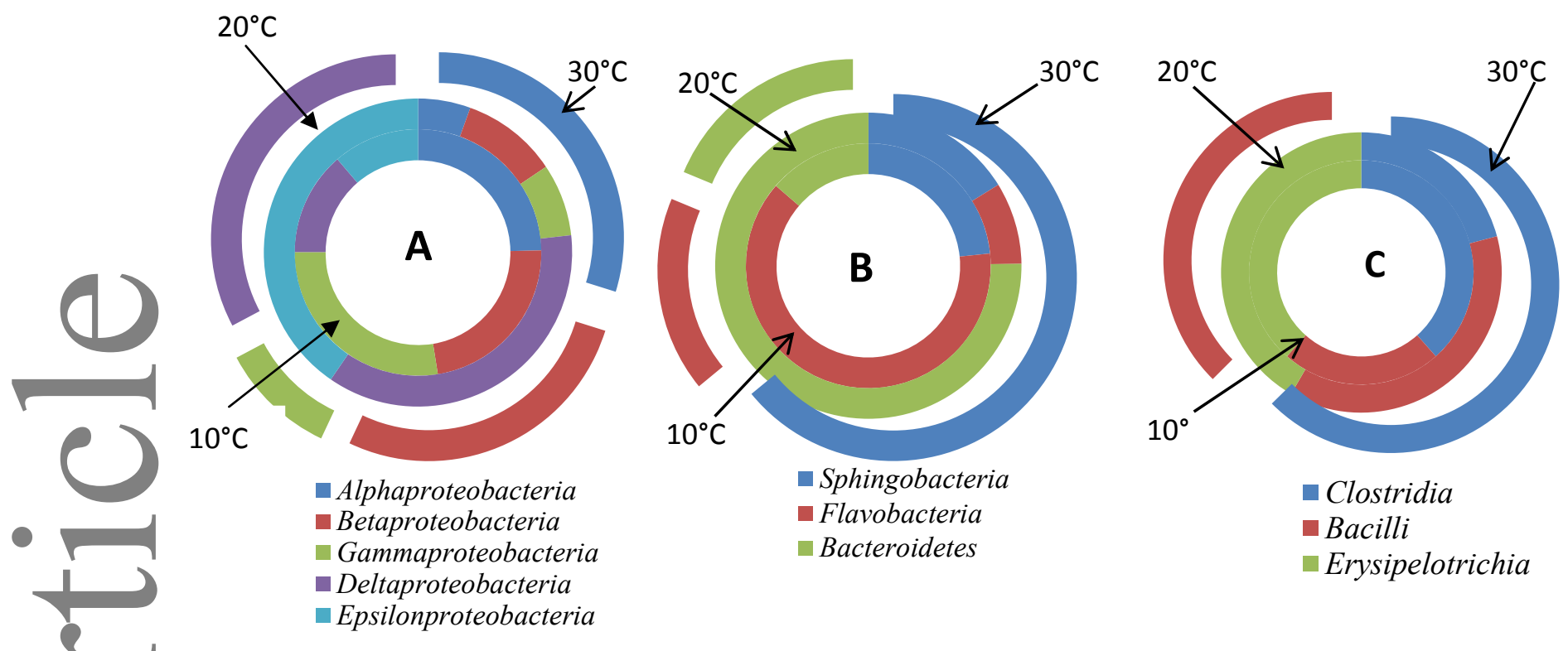

Fig. 6 


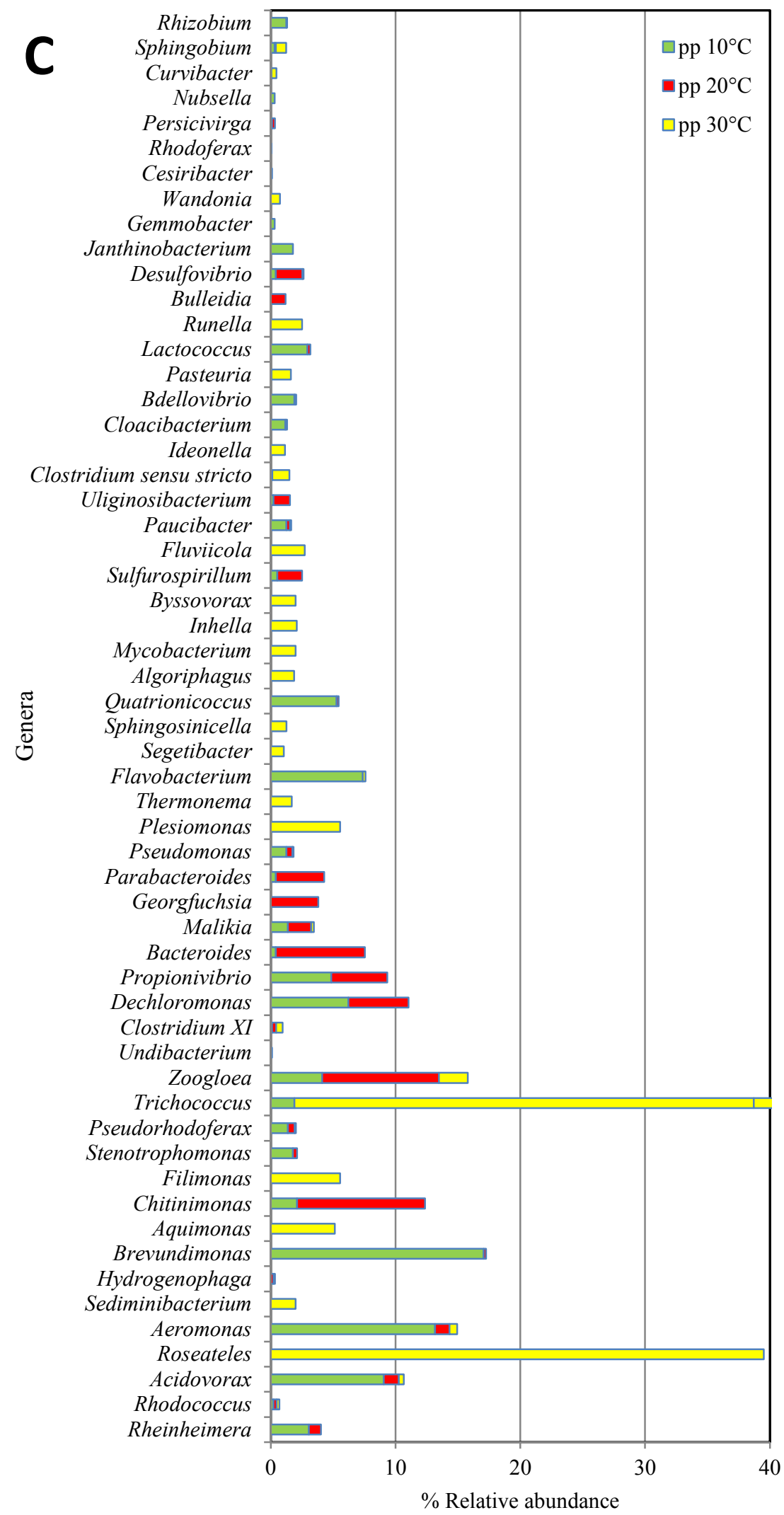

Fig. 7

This article is protected by copyright. All rights reserved. 


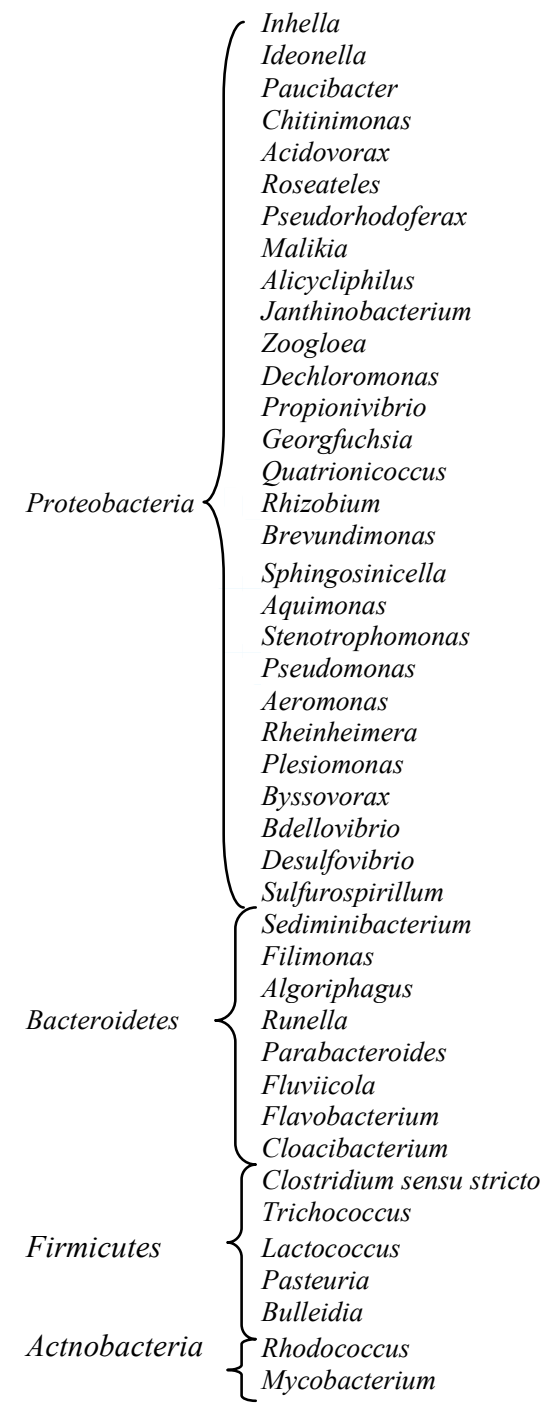

\begin{tabular}{|c|c|c|}
\hline $10^{\circ} \mathrm{C}$ & $20^{\circ} \mathrm{C}$ & $30^{\circ} \mathrm{C}$ \\
\hline 0.00 & 0.00 & 2.1 \\
\hline 0.00 & 0.00 & 1.15 \\
\hline 1.26 & 0.28 & 0.1 \\
\hline 2.11 & 10.2 & 0.00 \\
\hline 9.06 & 1.19 & 0.42 \\
\hline 0.00 & 0.00 & 39.6 \\
\hline 1.37 & 0.55 & 0.1 \\
\hline 1.37 & 1.88 & 0.21 \\
\hline 0.00 & 0.00 & 1.89 \\
\hline 1.79 & 0.00 & 0.00 \\
\hline 4.11 & 9.38 & 2.31 \\
\hline 6.22 & 4.83 & 0.00 \\
\hline 4.85 & 4.5 & 0.00 \\
\hline 0 & 3.81 & 0.00 \\
\hline 5.27 & 0.18 & 0.00 \\
\hline 1.26 & 0.05 & 0.00 \\
\hline 17.1 & 0.18 & 0.00 \\
\hline 0.00 & 0.00 & 1.26 \\
\hline 0.00 & 0.00 & 5.14 \\
\hline 1.79 & 0.32 & 0.00 \\
\hline 1.26 & 0.46 & 0.1 \\
\hline 13.2 & 1.15 & 0.63 \\
\hline 3.06 & 0.97 & 0.00 \\
\hline 0.00 & 0.00 & 5.56 \\
\hline 0.00 & 0.00 & 1.99 \\
\hline 1.9 & 0.14 & 0.00 \\
\hline 0.42 & 2.11 & 0.1 \\
\hline 0.53 & 1.98 & 0.00 \\
\hline 0.00 & 0.00 & 1.99 \\
\hline 0.00 & 0.00 & 5.56 \\
\hline 0.00 & 0.00 & 1.89 \\
\hline 0.00 & 0.00 & 2.52 \\
\hline 0.42 & 3.86 & 0.00 \\
\hline 0.00 & 0.00 & 2.73 \\
\hline 7.38 & 0.00 & 0.21 \\
\hline 1.16 & 0.14 & 0.00 \\
\hline 0.00 & 0.14 & 1.36 \\
\hline 1.9 & 36.8 & 3.15 \\
\hline 2.95 & 0.23 & 0.00 \\
\hline 0.00 & 0.05 & 1.57 \\
\hline 0.00 & 1.19 & 0.00 \\
\hline 0.21 & 0.28 & 0.21 \\
\hline 0.11 & 0.00 & 1.99 \\
\hline
\end{tabular}

Fig. 8

This article is protected by copyright. All rights reserved. 

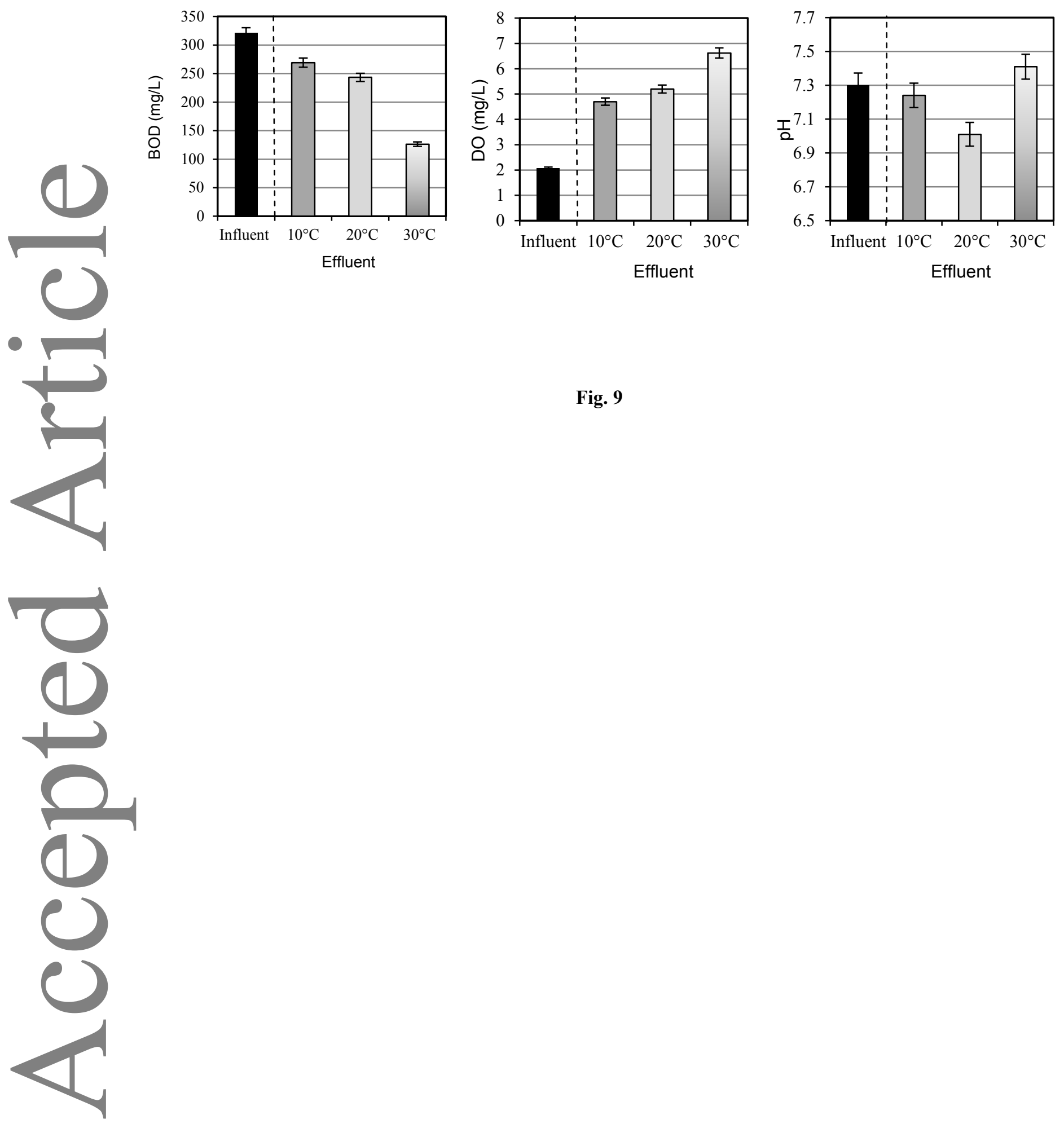

Fig. 9 